\title{
ARTE-TEXTO: \\ UM INUSITADO MERGULHO POR ENTRE IMAGENS, CONCEITOS E EXPERIÊNCIAS
}

ART-TEXT:
AN UNUSUAL DIVING IN PICTURES,
CONCEPTS AND EXPERIENCES
ARTE-TEXTO:
UN BUCEO INUSUAL ENTRE IMÁGENES,
CONCEPTOS Y EXPERIENCIAS

Camilo Floriano Riani Costa ${ }^{1}$, Cesar Donizetti Pereira Leite ${ }^{2}$

\section{RESUMO}

A arte tem ocupado um espaço crescente nas mais distintas discussões em torno da constituição do sujeito, seja pelo viés da experiência, seja pelo da subjetivação, entre muitos outros. Em meio a um cenário pautado pela potência de incontáveis linhas de fuga, existiria um percurso possível para dizer da arte, com arte, pela arte, sendo arte? A partir de reflexões e mergulhos da arte-tese Caricatas: arte-rosto-humor-experiência, bem como de iniciativas do grupo Imago (Unesp/Rio Claro), em diálogo com Deleuze, Guattari, Foucault e outros, nasce o presente arte-artigo, constituído integralmente por composições visuais, que levam a espaços em que arte, humor e experiência passam a tecer novas nuances, novas texturas, novas interrogações...

PALAVRAS-CHAVE: Arte. Visual. Humor. Experiência. Subjetivação.

\section{ABSTRACT}

Art has occupied a growing space in the most distinct discussions about the constitution of the subject, whether by the bias of experience, whether by the subjectivity, among many others. Amidst a scenario lined with the power of countless escape routes, would there be a possible route to say of art, art, art, art? From the reflections and dives of the art-thesis 'Caricats: art-face-humor-experience', as well as initiatives from the Imago group (Unesp / Rio Claro), in dialogue with Deleuze, Guatarri, Foucault and others, an art-article composed entirely of visual compositions, which takes us to a space where art, humor and experience come to weave new nuances, new textures, new questions...

KEYWORDS: Art. Visual. Humor. Experience. Subjectivity.

\section{RESUMEN}

La arte ha ocupado un espacio creciente en las más diversas discusiones en torno a la constitución del sujeto, ya sea desde la perspectiva de la experiencia, ya sea por la subjetividad, entre muchos otros. En medio de un escenario marcado por un sinnúmero de líneas eléctricas de vuelo, no habría una posible manera de de decir el arte, con el arte, el arte, y el arte? A partir de las reflexiones y inmersiones de la arte-tesis 'Caricatas: arte-cara-humor-experiencia', así como iniciativas del Grupo Imago (UNESP / Rio Claro), en diálogo con Deleuze, Guattari, Foucault y otros, ha nacido el arte-artículo totalmente establecido por composiciones visuales, lo que nos lleva a un lugar donde el arte, el humor y la experiencia comienzan a tejer nuevos matices, nuevas texturas, nuevas interrogaciones...

PALABRAS CLAVE: Arte. Visual. Humor. Experiencia. Subjetividad.

\footnotetext{
${ }^{1}$ Doutor em Educação - Universidade Estadual Paulista "Júlio de Mesquita Filho" (UNESP). São Paulo, SP-Brasil. Artista plástico, Caricaturista, Pesquisador e Professor universitário - Universidade Metodista de Piracicaba, Faculdade de Comunicação, Curso de Publicidade e Propaganda (UNIMEP). Piracicaba, SP - Brasil. E-mail: camiloriani@gmail.com 2 Doutor em Educação - Universidade Estadual de Campinas (UNICAMP) - Campinas, SP - Brasil. Professor Adjunto Universidade Estadual Paulista "Júlio de Mesquita Filho" (UNESP). São Paulo, SP - Brasil. E-mail: mvhleite@uol.com.br
} Submetido em: 04-11-2016 - Aceito em: 03/05/2017

(C) ETD - Educação Temática Digital Campinas, SP $\quad$ v.20 $\quad$ n.3 $\quad$ p. 679-698 jul./set.2018




\section{OetD}

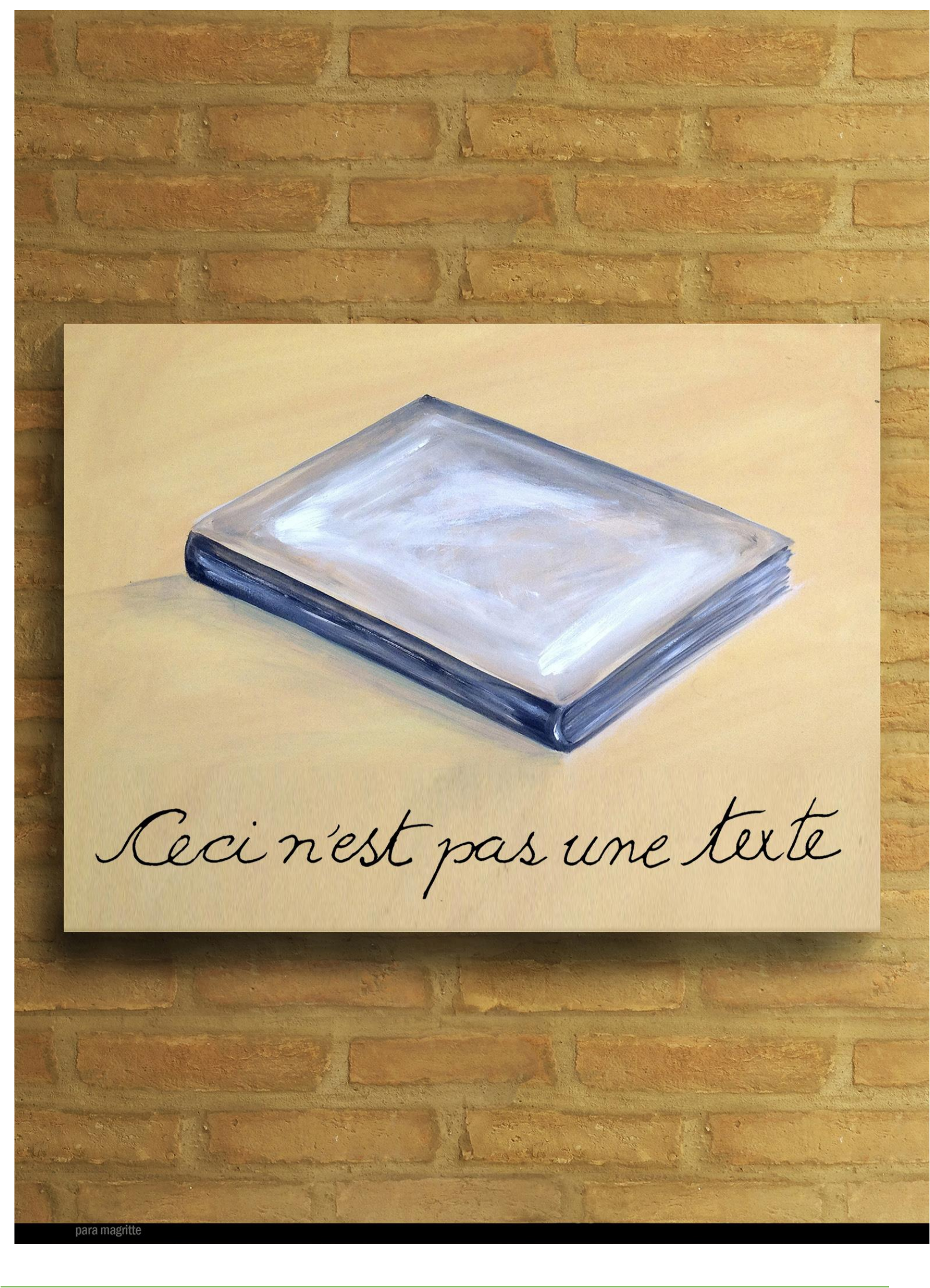

Campinas, SP

v. 20

n.3

p. $679-698$

jul./set.2018 


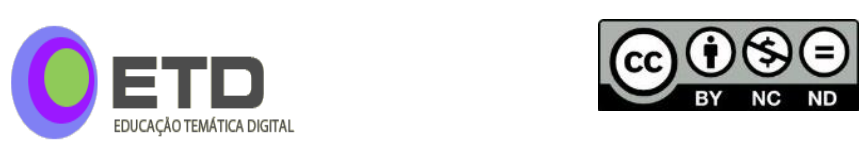

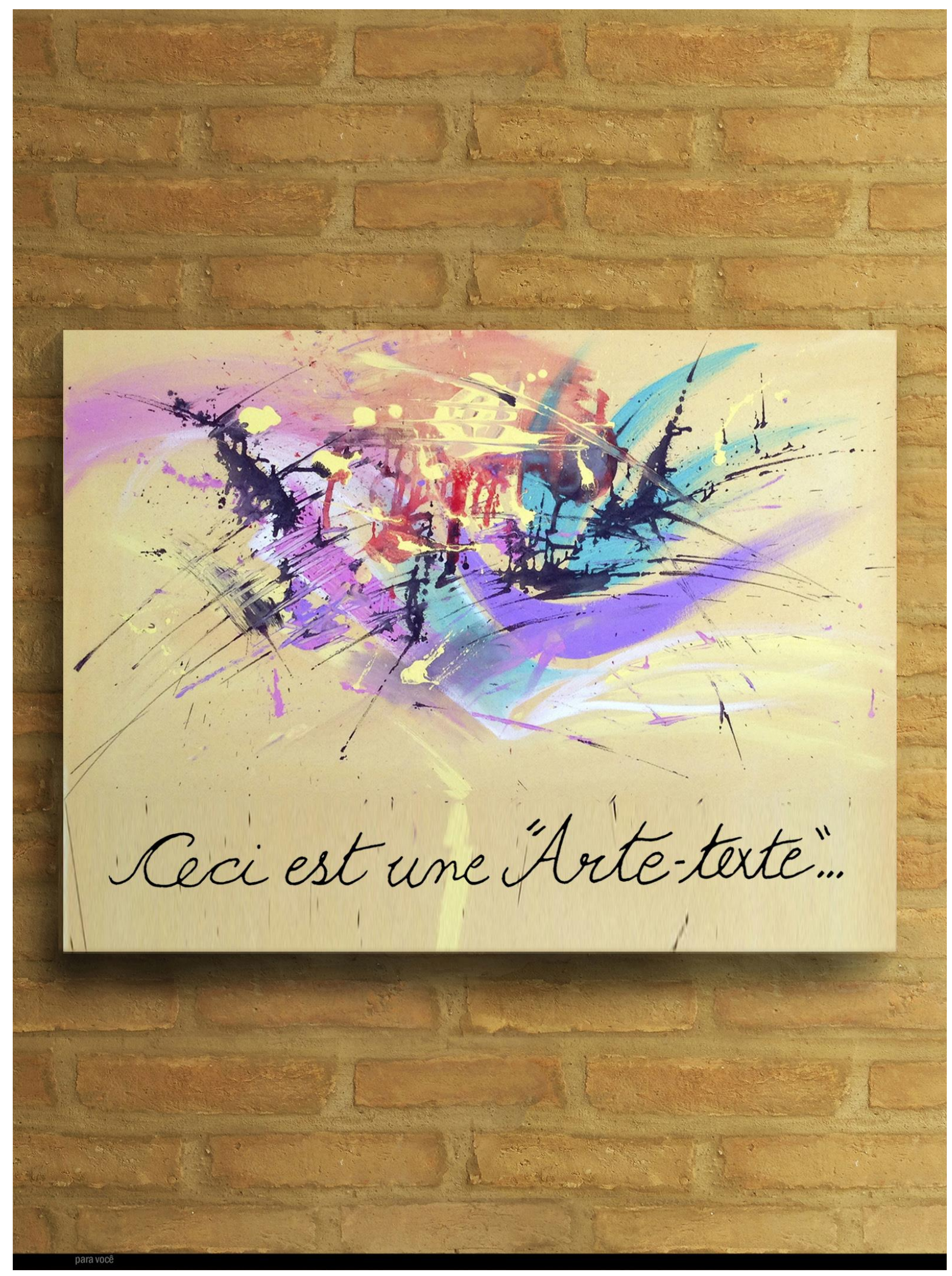




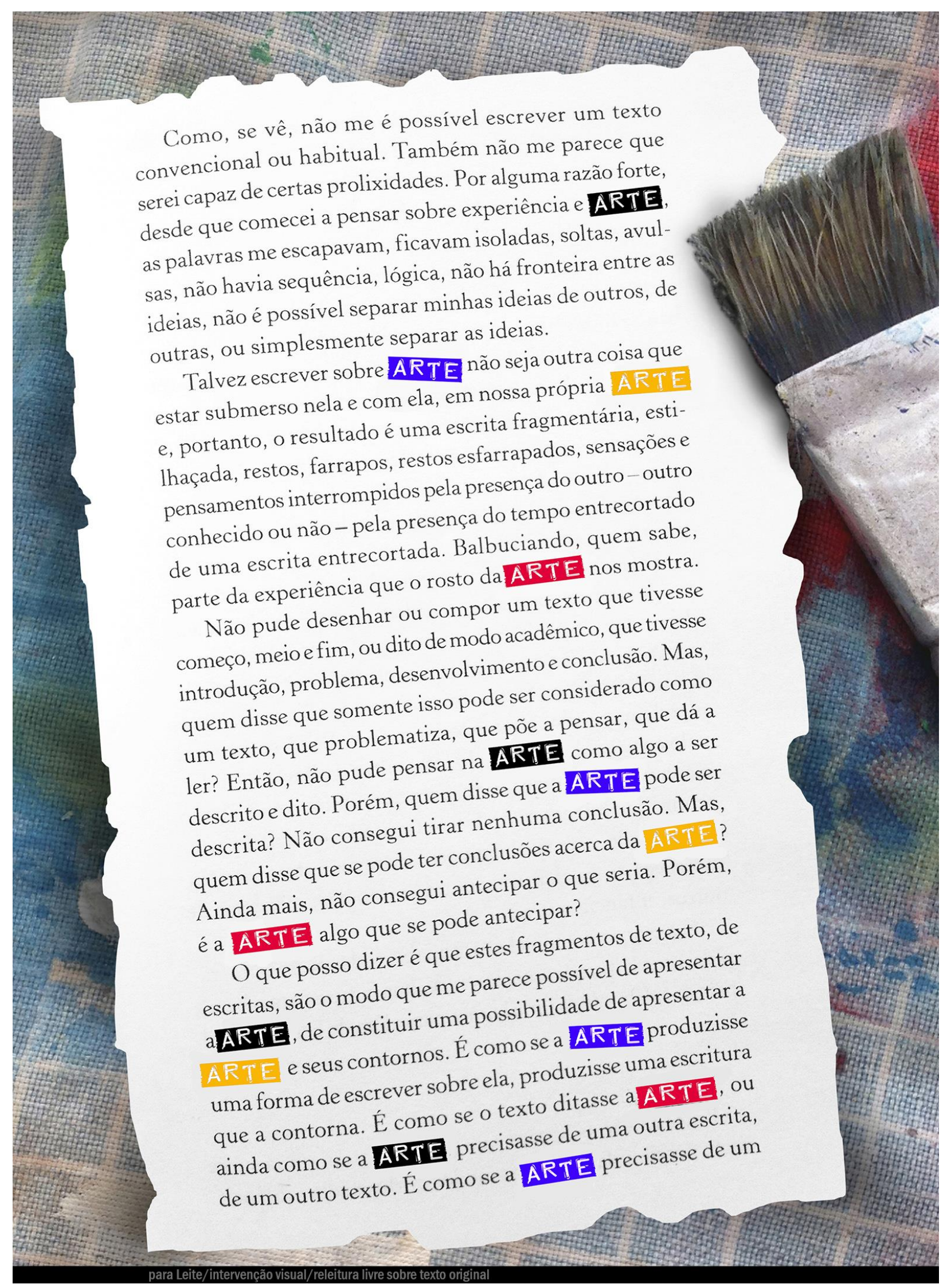




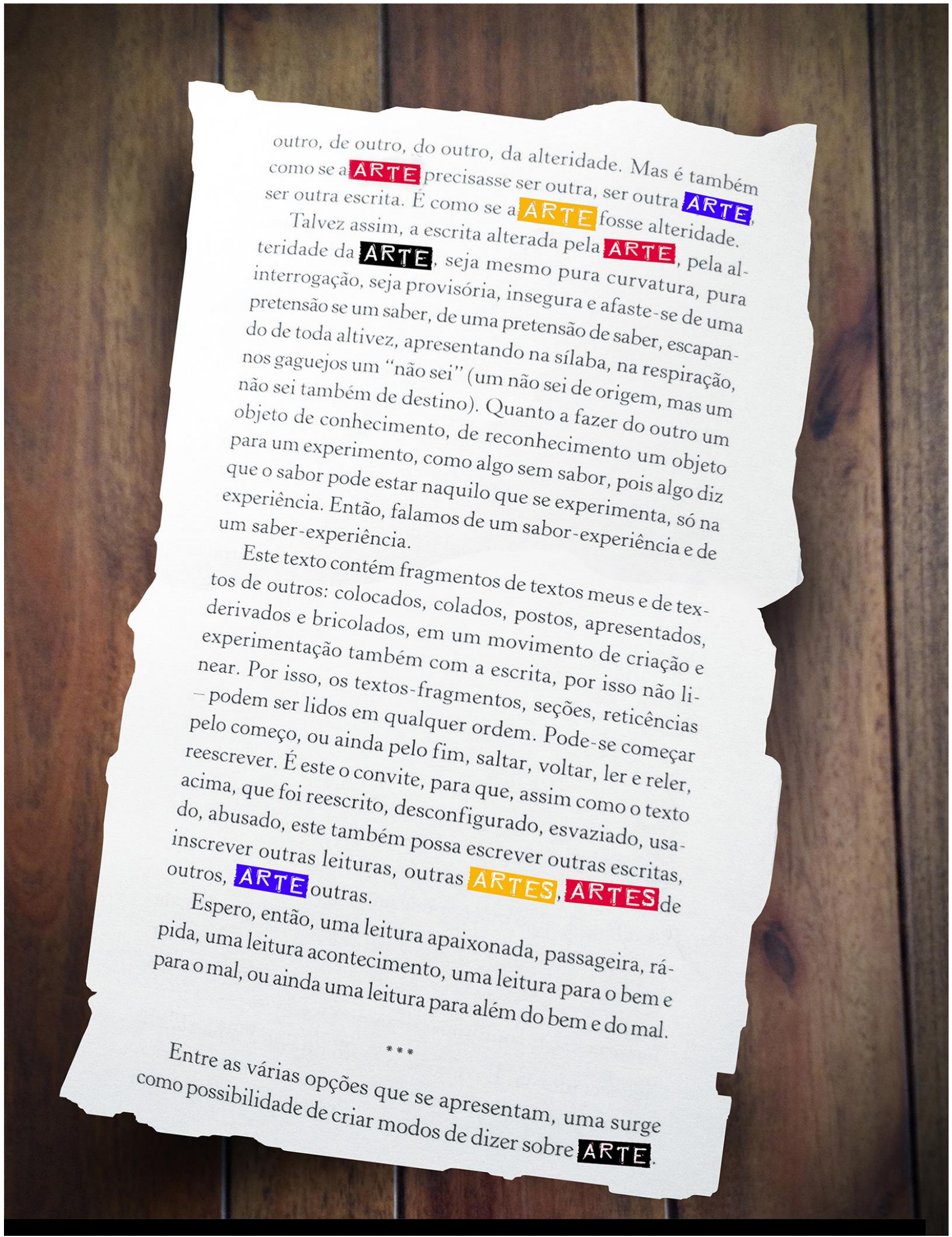




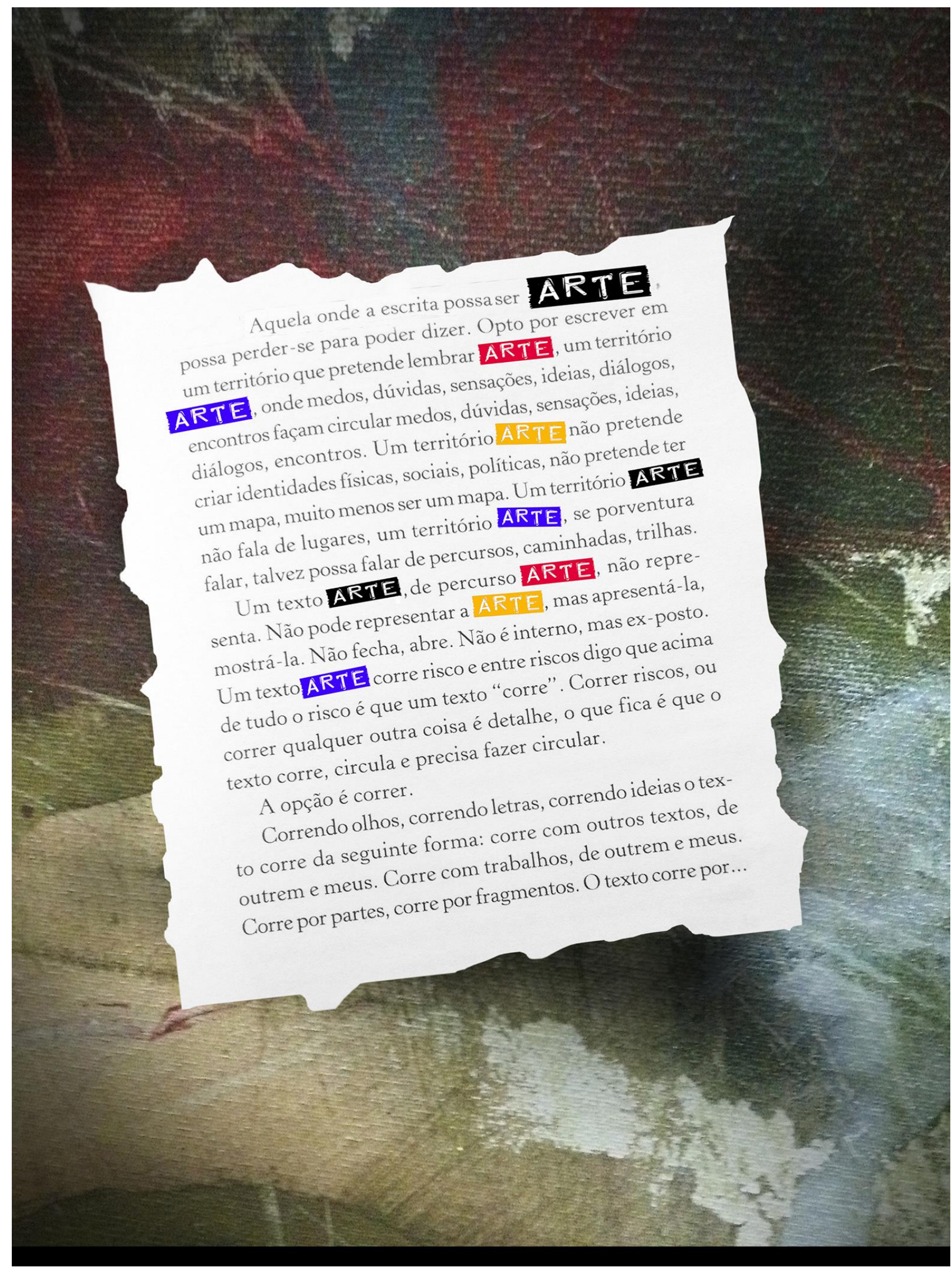




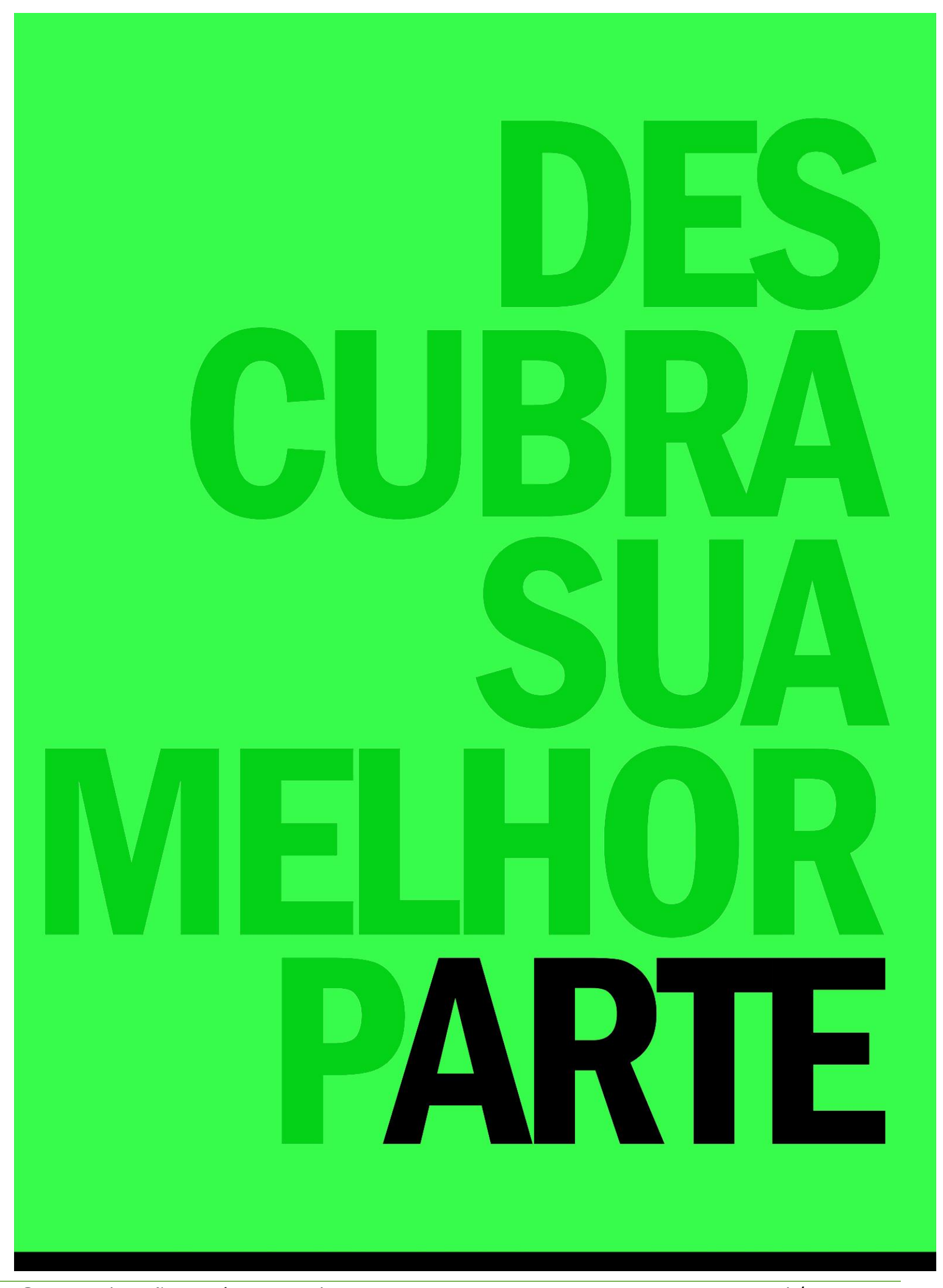

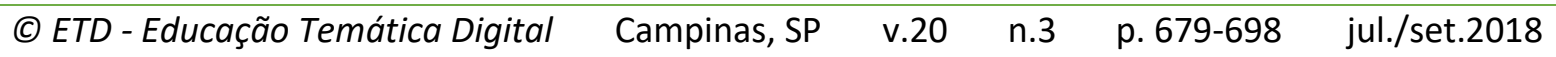




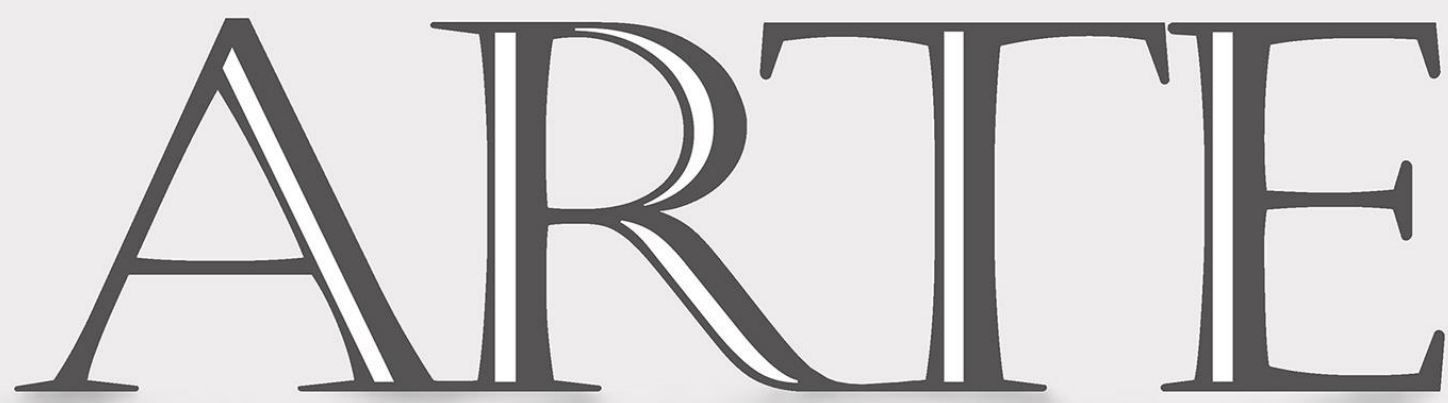




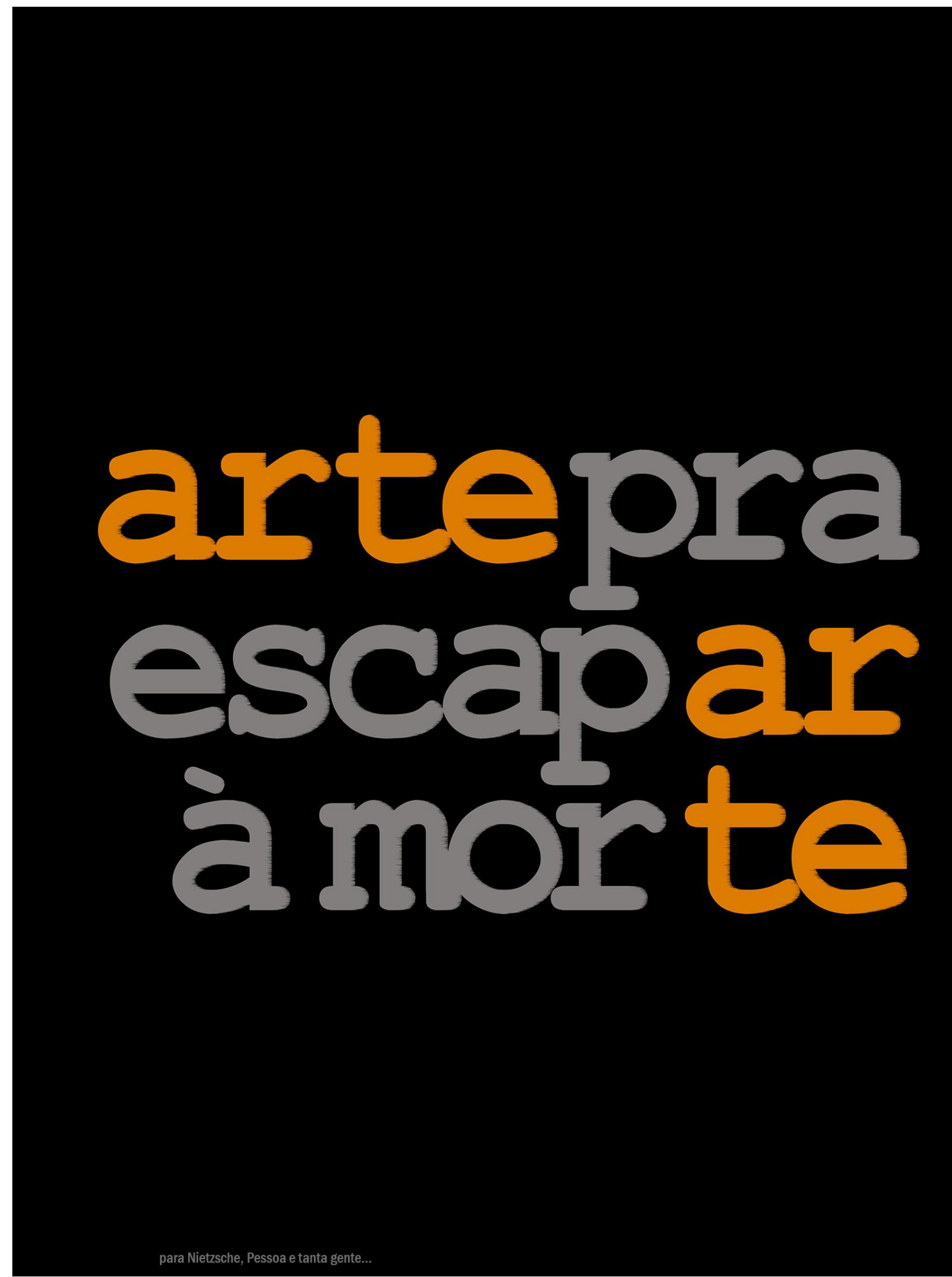




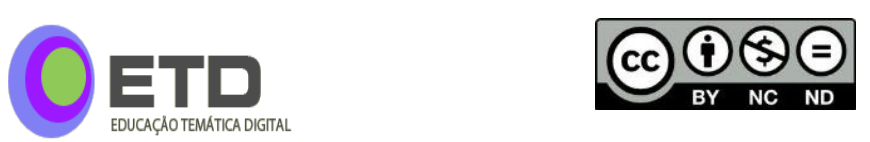

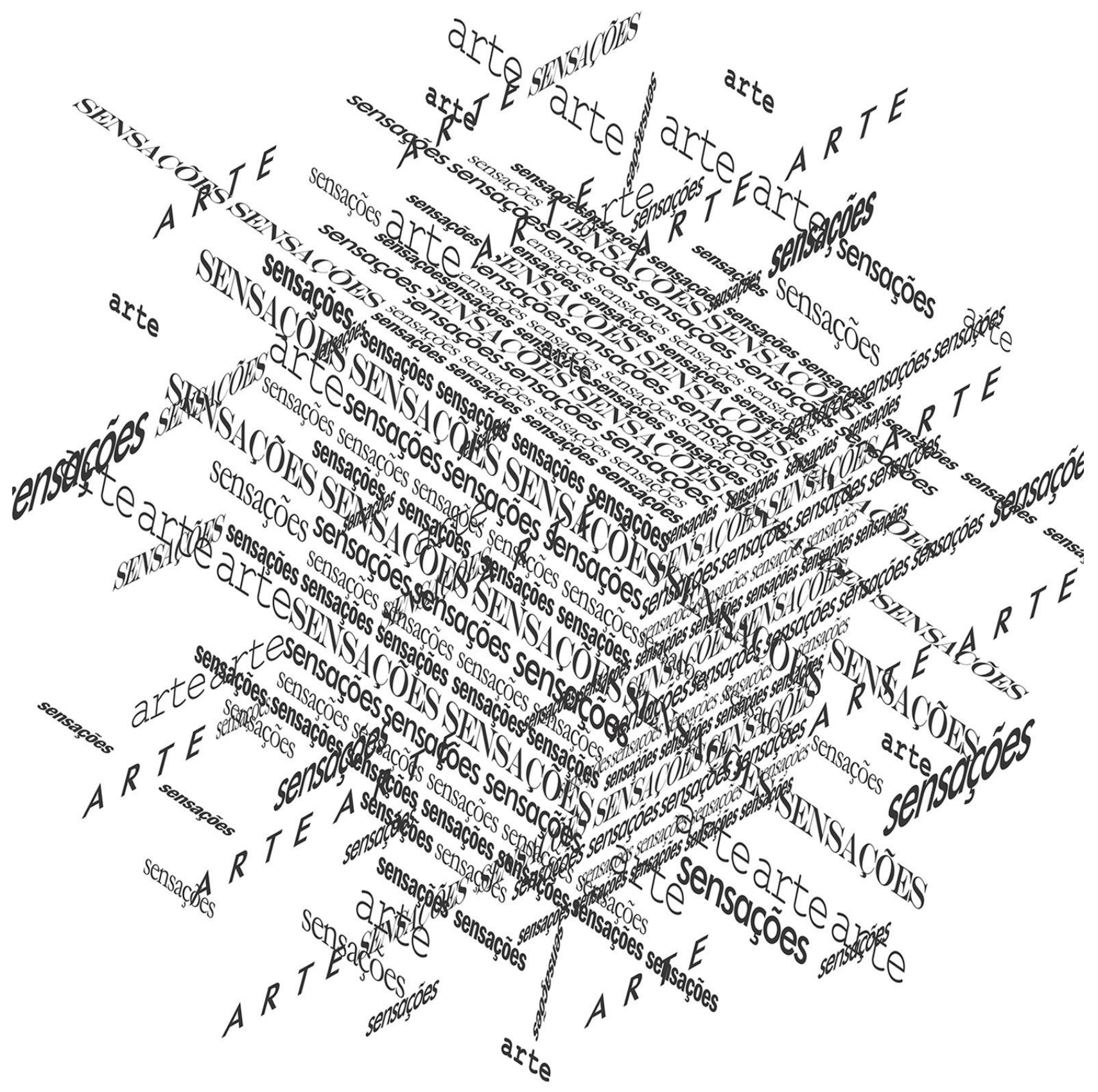

(C) ETD - Educação Temática Digital Campinas, SP $\quad$ v.20 $\quad$ n.3 $\quad$ p. 679-698 jul./set.2018 


\section{OetD}

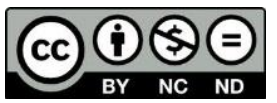
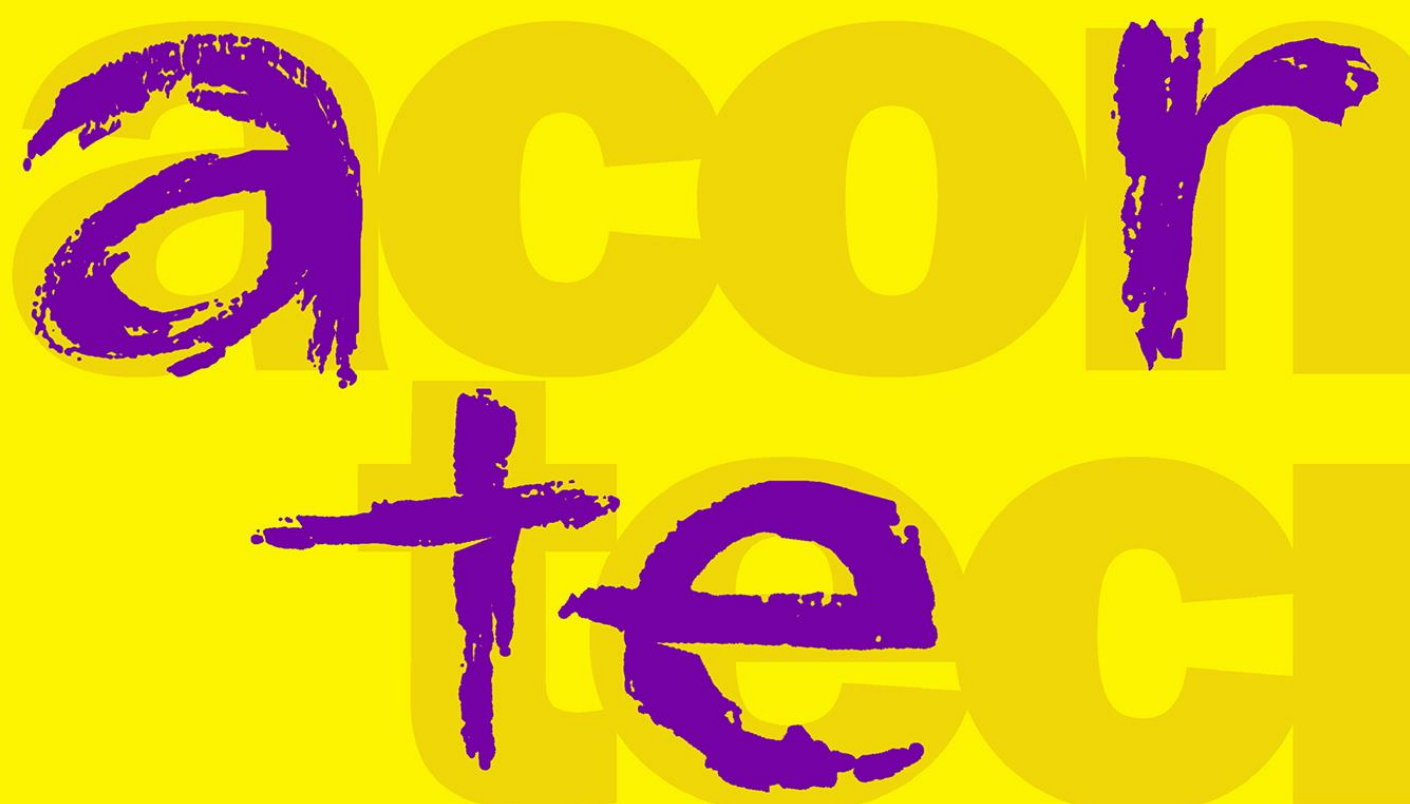


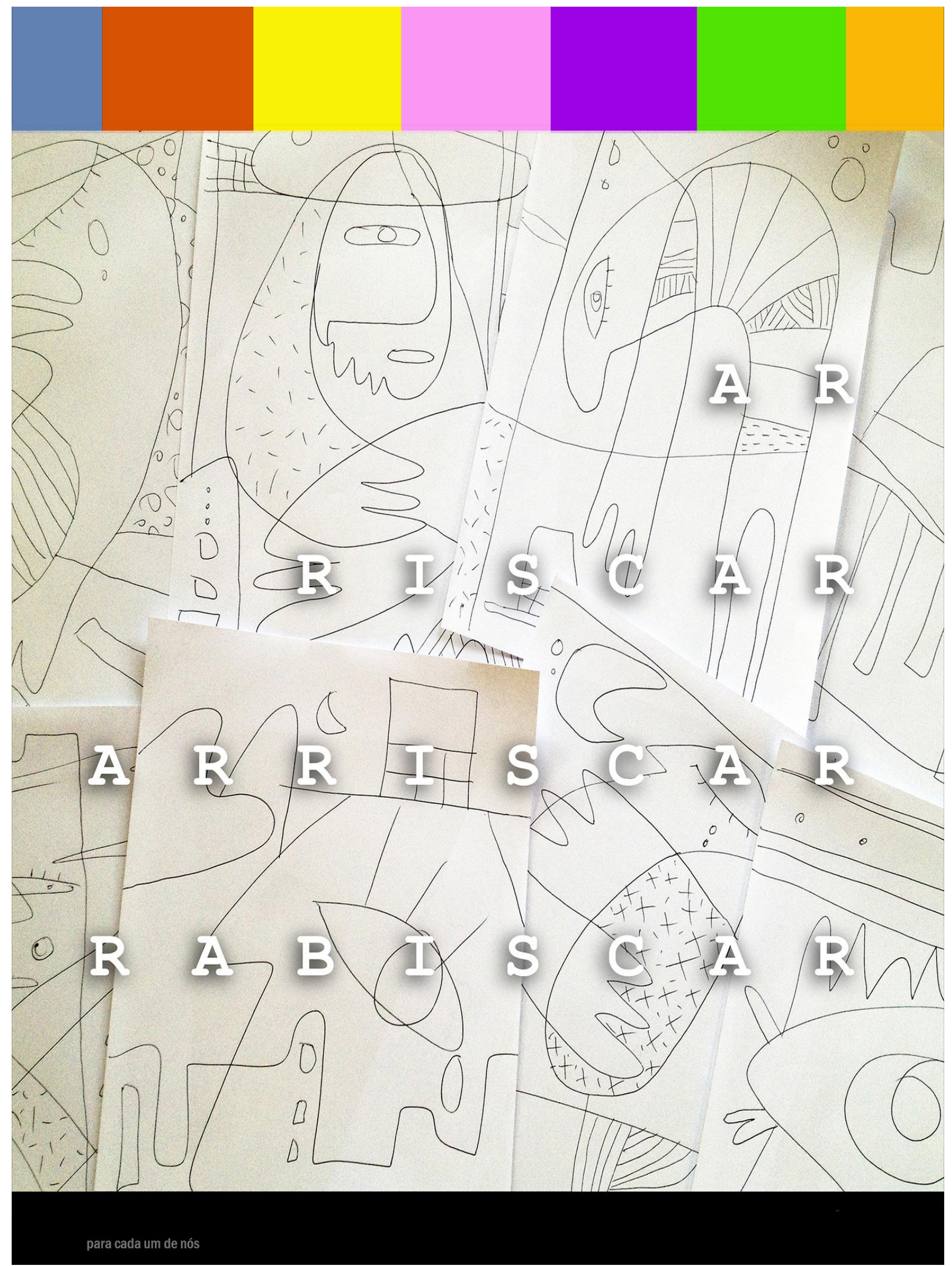




\section{Oetr}

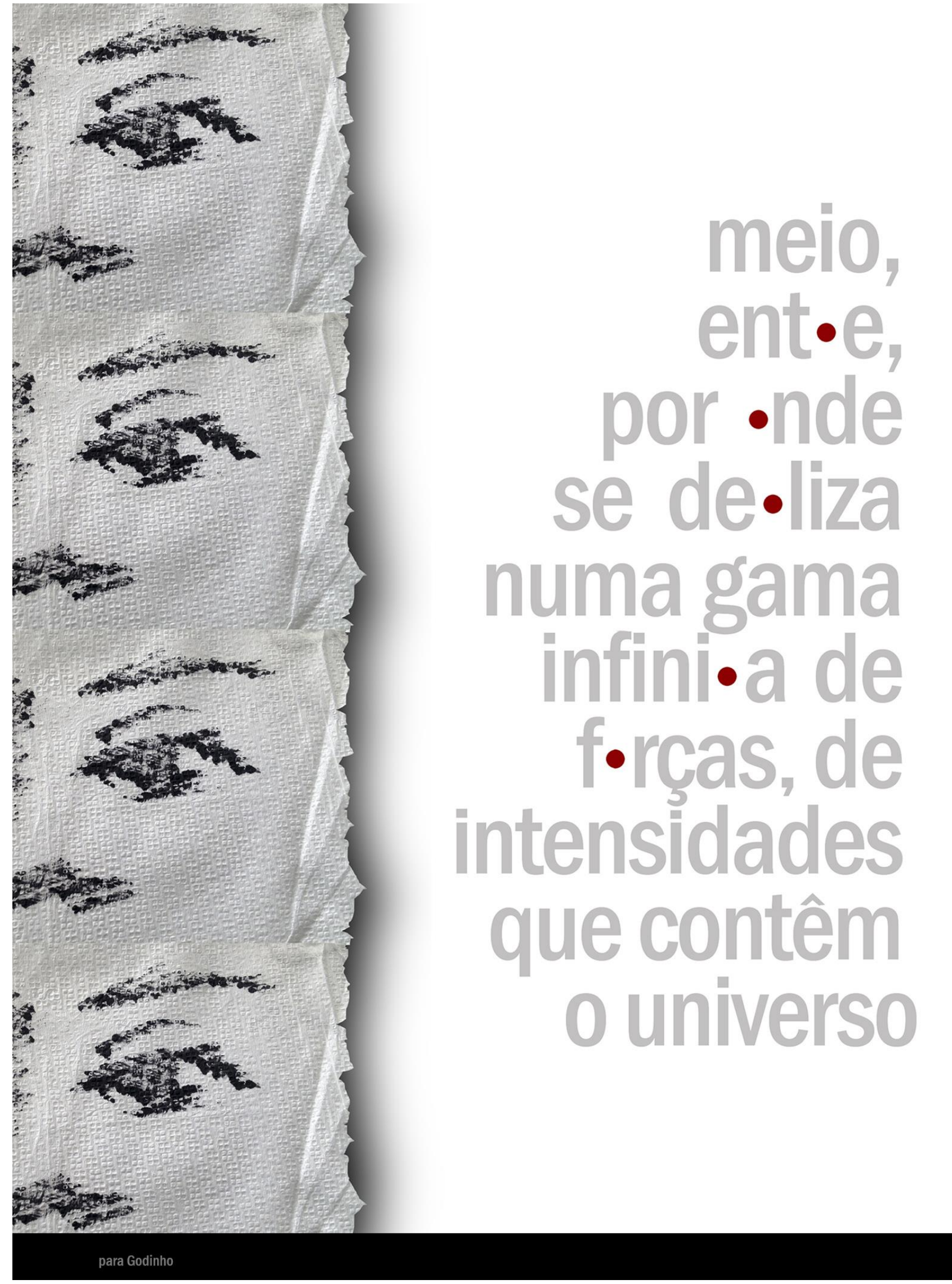

(C) ETD - Educação Temática Digital Campinas, SP

n.3 p. $679-698 \quad$ jul./set.2018 


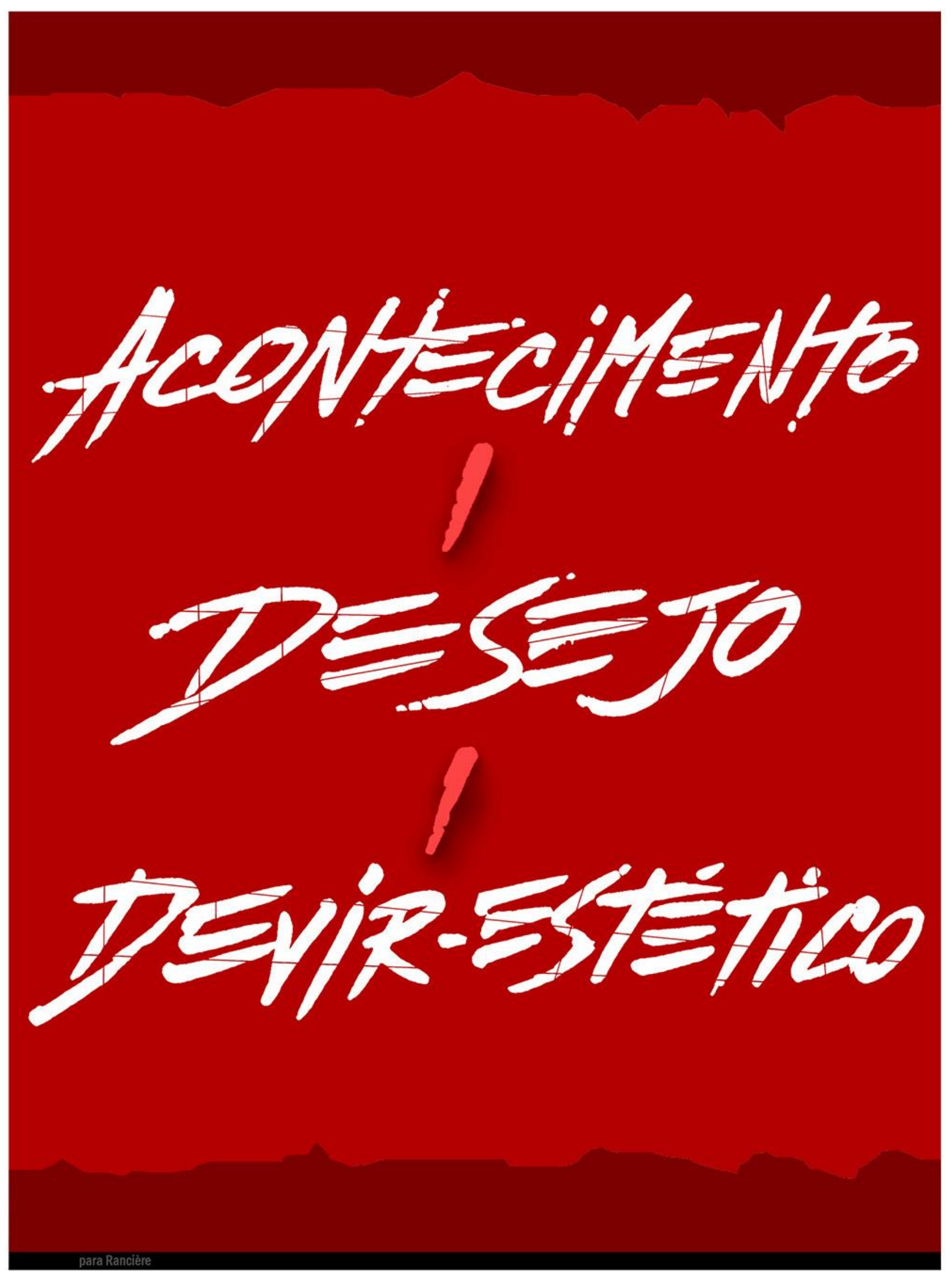

(C) ETD - Educação Temática Digital

Campinas, SP

v.20

n.3

p. $679-698$

jul./set.2018 


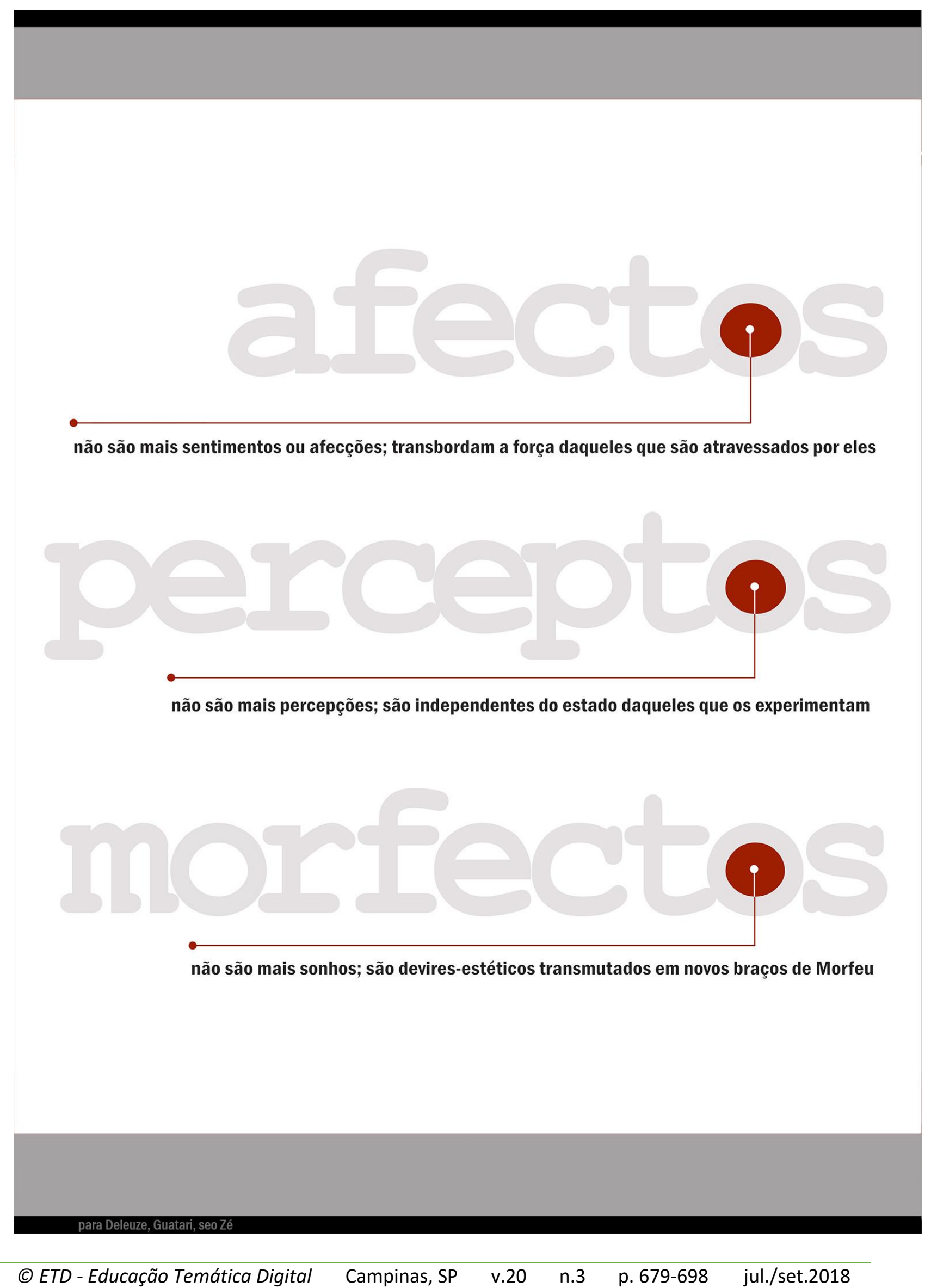




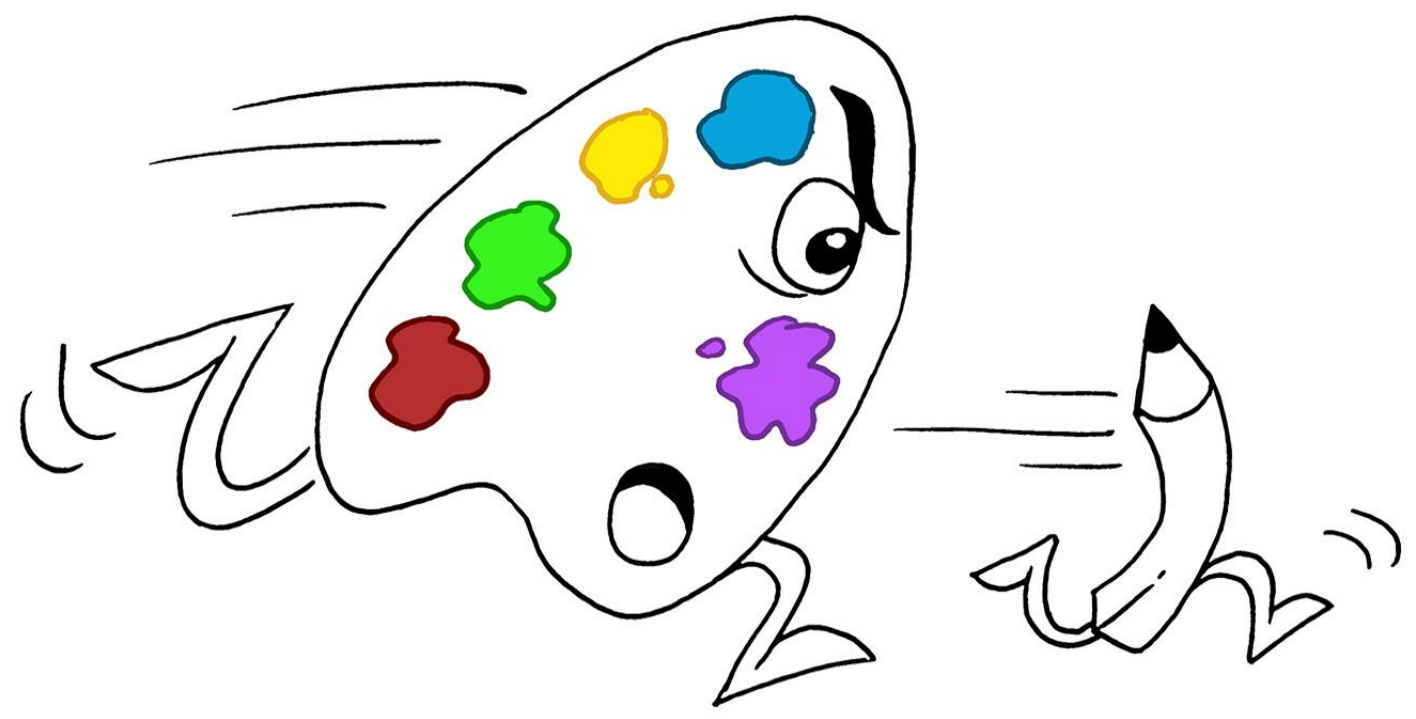

\section{artemenorartemenorartemenorarte}

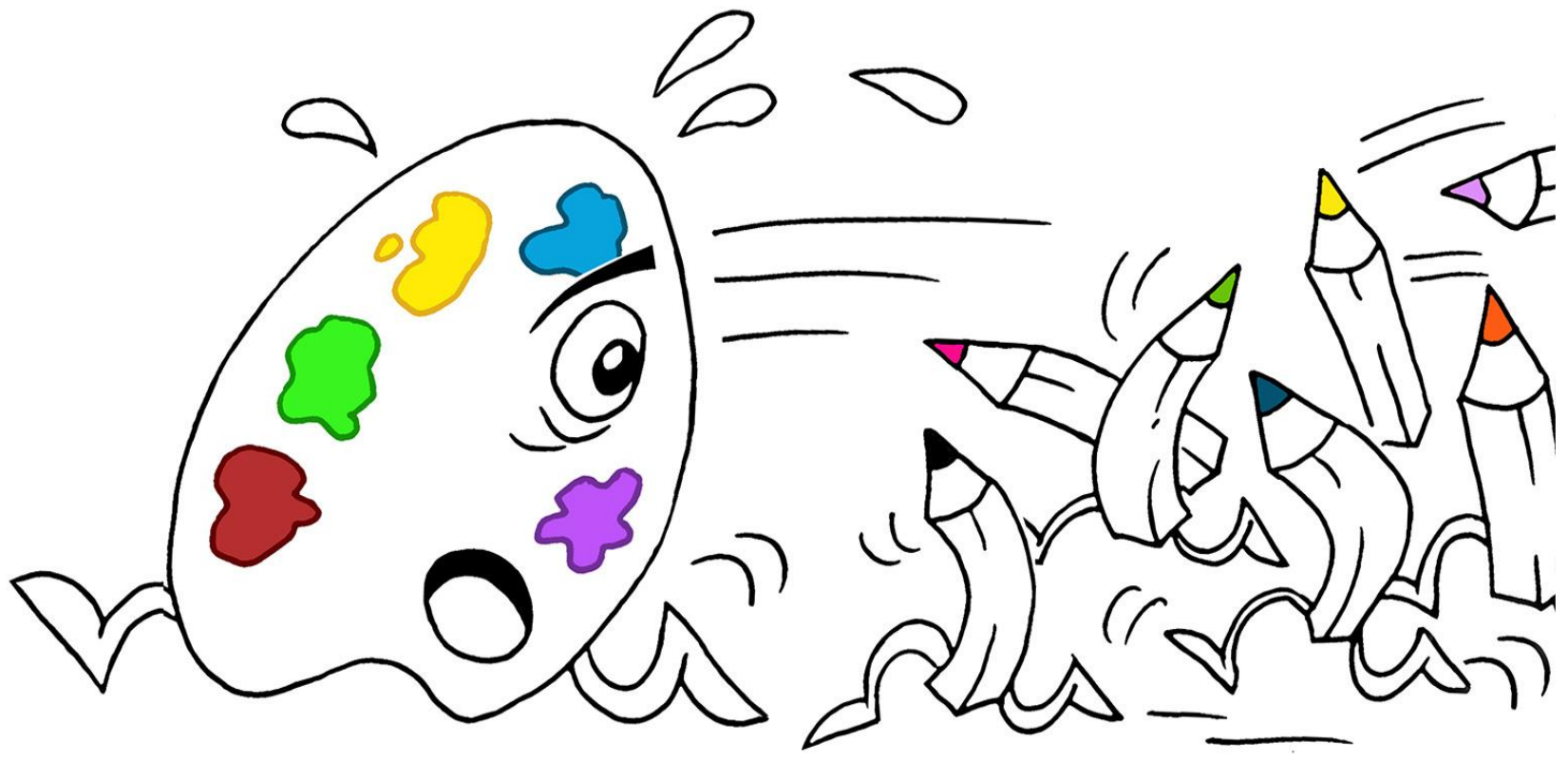

$\begin{array}{llllll}\text { (C) ETD - Educação Temática Digital } & \text { Campinas, SP } & \text { v.20 } & \text { n.3 } & \text { p. 679-698 } & \text { jul./set.2018 }\end{array}$ 


\section{○ETD}

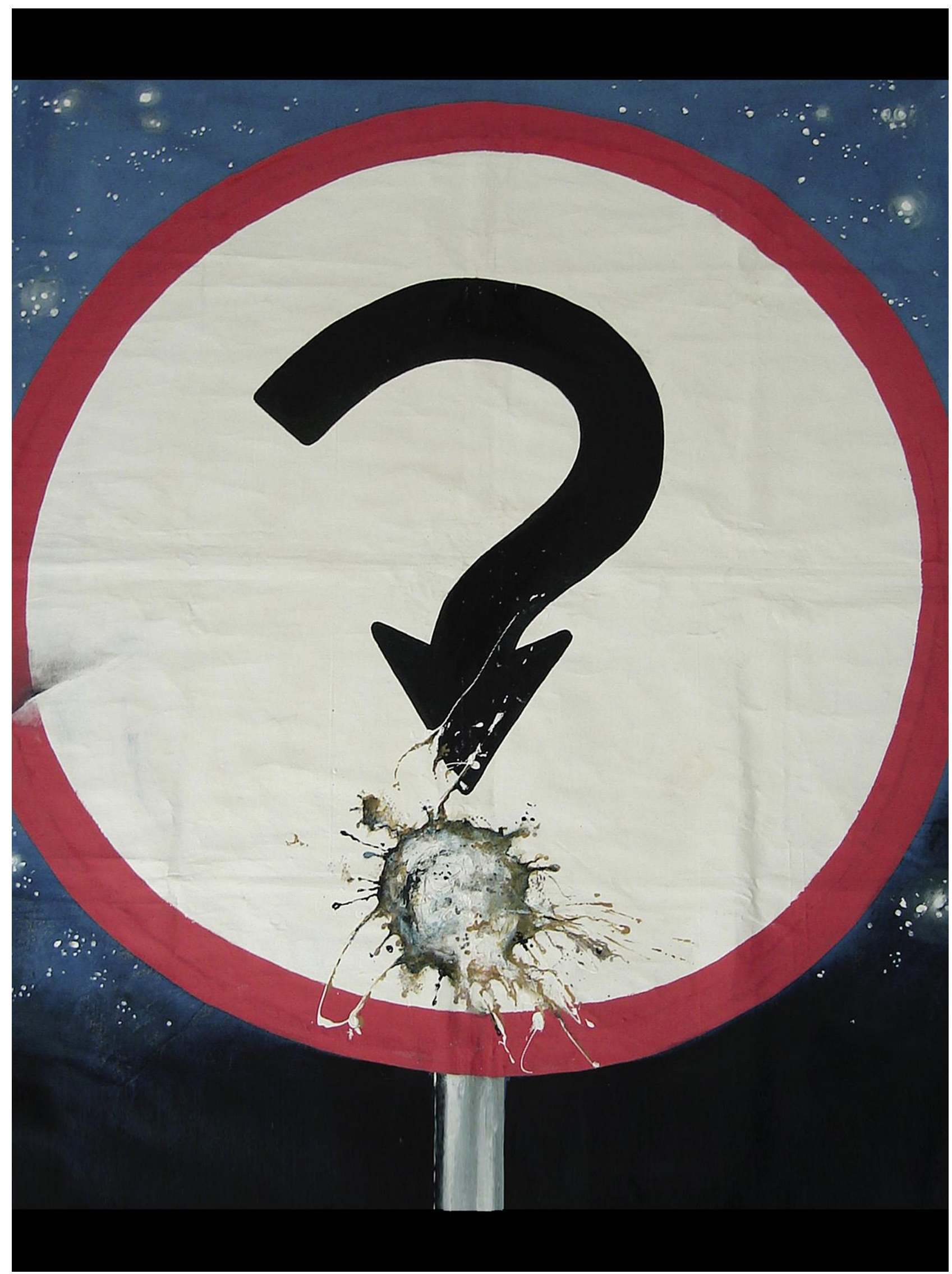

(C) ETD - Educação Temática Digital

Campinas, SP

v. 20

n.3

p. $679-698$

jul./set.2018 


\section{Oetr @O}

ARTIGO

DOI: $\underline{10.20396 / \text { etd.v20i3.8647476 }}$

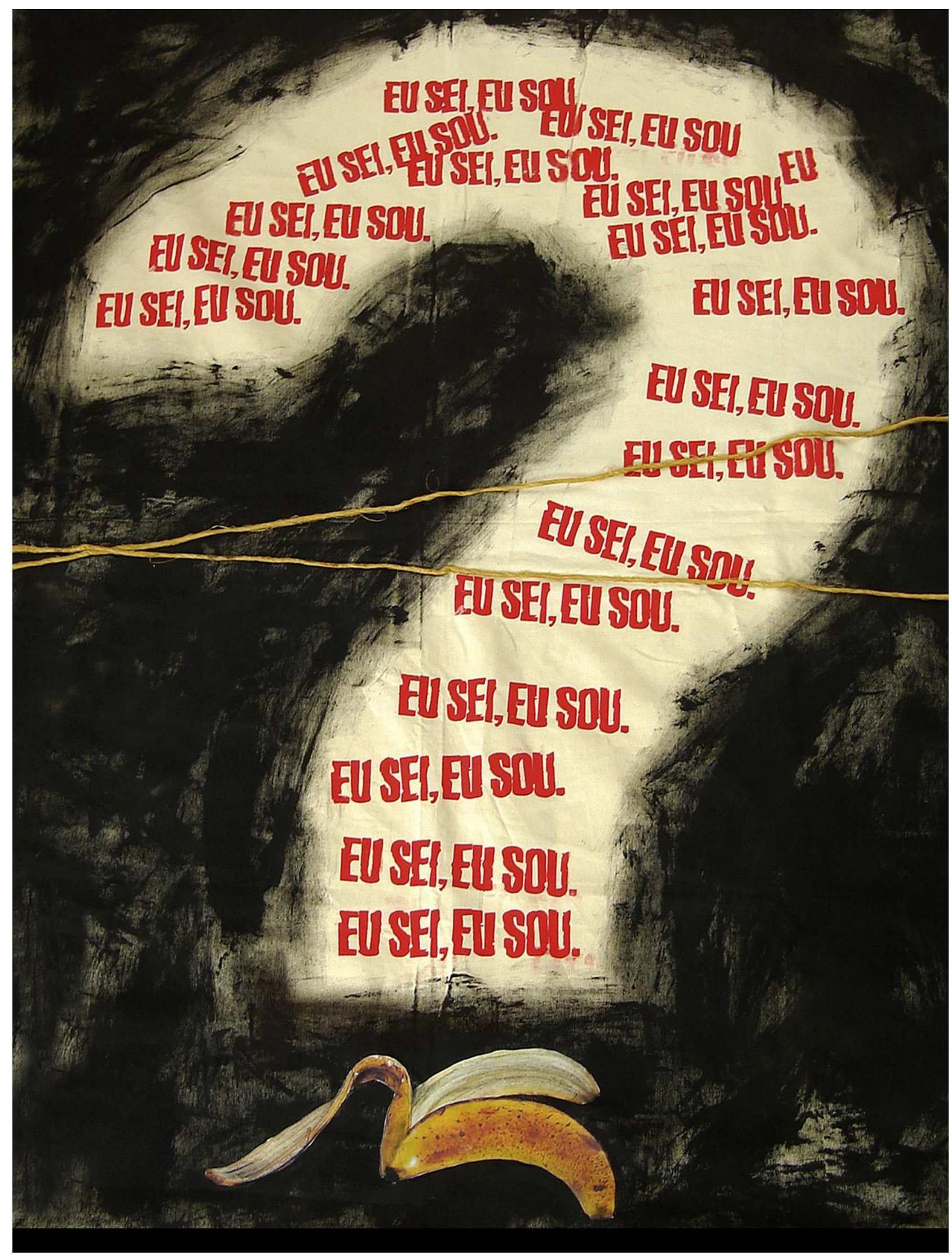




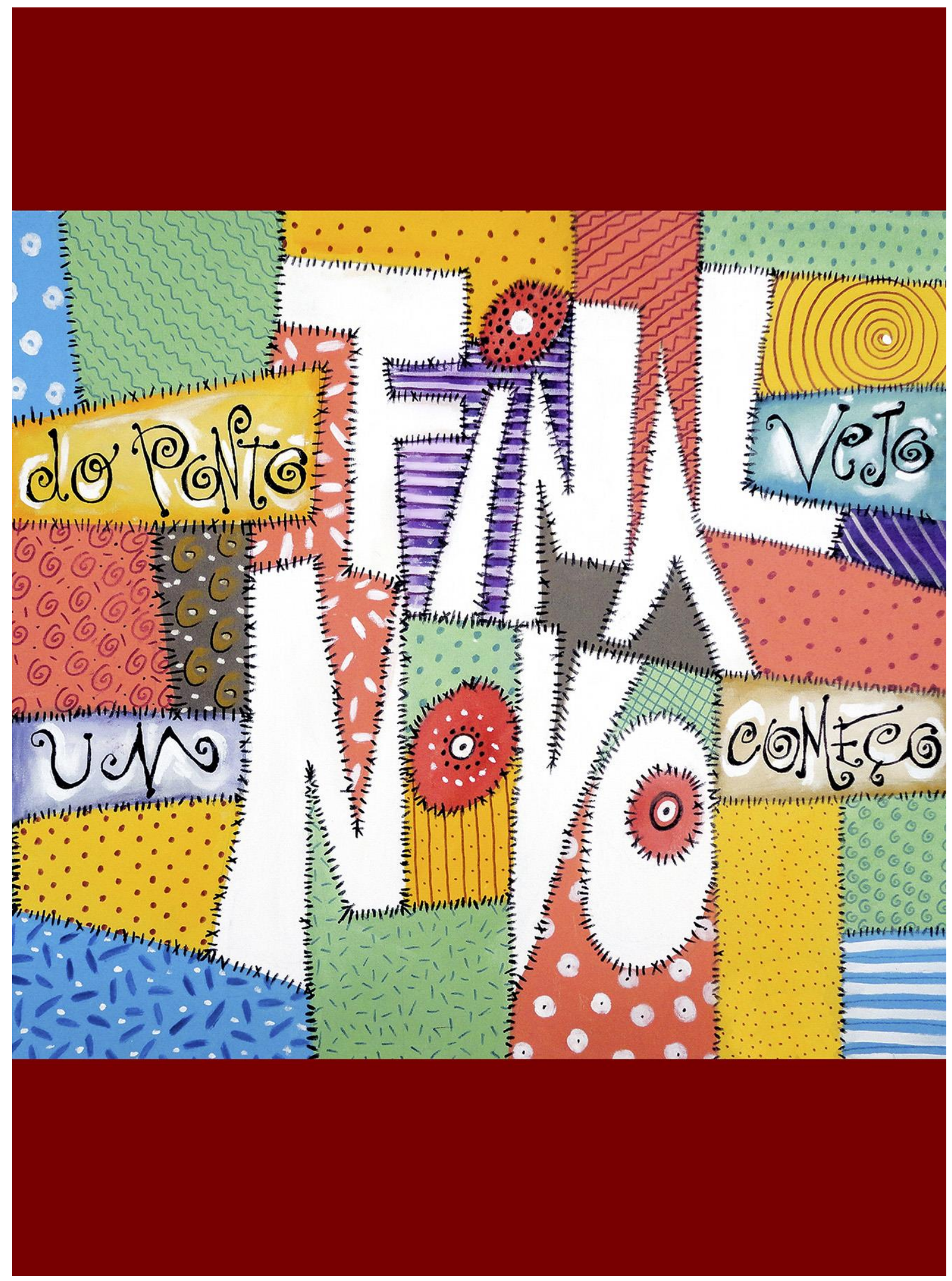

(C) ETD - Educação Temática Digital Campinas, SP

$\begin{array}{ll}\text { v.20 } & \text { n.3 }\end{array}$

p. $679-698$ jul./set.2018 


\section{REFERÊNCIAS ${ }^{\mathrm{i}}$}

AGAMBEN, Giorgio. Infância e história: destruição da experiência e origem da história. Belo Horizonte: UFMG, 2005.

BENJAMIN, W. Textos escolhidos / Walter Benjamin, Theodor W. Adorno, Jürgen

Habermas. 2. ed. São Paulo: Abril Cultural, 1983.

DELEUZE, Gilles; GUATTARI, Félix. Kafka: por uma literatura menor. Tradução Júlio Castañon Guimarães. Rio de Janeiro: Imago, 1977.

DELEUZE, Gilles; GUATTARI, Félix. Mil platôs: capitalismo e esquizofrenia. São Paulo: Ed.34, 1996. v.3.

DELEUZE, Gilles; GUATTARI, Félix. O que é filosofia. Tradução Bento Prado Jr. e Alberto Alonso Munoz. Rio de Janeiro: Ed.34, 1992. (Coleção Trans).

FOUCAULT, Michel. Sobre a genealogia da ética. Uma revisão do trabalho. In: RABINOW, Paul; DREYFUS, Hubert. Michel Foucault. Uma trajetória filosófica. Para além do estuturalismo e da hermenêutica. Rio de Janeiro: Forense Universitária, 1995.

GALLO, Sílvio. mínimo múltiplo comum. In: RIBETTO, Anelice (Org.). políticas, poéticas e práticas pedagógicas (com minúsculas). Rio de Janeiro: Lamparina; Faperj, 2014.

GODINHO, Ana. Como desfazer para si próprio o seu rosto? Cadernos de Subjetividade, Núcleo de Estudos e Pesquisas da Subjetividade/ Programa de Estudos Pós-Graduados em Psicologia Clínica/PUC-SP, São Paulo, 2010.

GODINHO, Ana. Devir rosto e abrir pensamento. In: OLIVEIRA DIAS, Suzana; MARQUES, Davina; AMORIM, Antonio Carlos (Org.). Conexões: Deleuze e arte e ciência e acontecimento e... Petrópolis, RJ: De Petrus; Brasília, DF: CNPq/MCT; Campinas: ALB, 2012.

LEITE, César D.P. Experitempos de experinfância: re-cortes de montimagens de-formação. Tese (Livre-Docência). Departamento de Educação, Universidade Estadual Paulista Júlio de Mesquita Filho-UNESP, Rio Claro, 2011.

PESSOA, Fernando. Heróstrato e a busca da imortalidade. Portugal: Assírio \& Alvim, 2000.

RANCIÈRE, Jacques. A partilha do sensível. Estética e Política. Rio de Janeiro: Editora 34, 2009.

RIANI, Camilo. Caricatas: arte-rosto-humor-experiência. Tese (Doutorado) - Programa de Pós-Graduação em Educação, Universidade Estadual Paulista Júlio de Mesquita Filho Universidade, Rio Claro, 2016. Orientador: Cesar Donizetti Pereira Leite.

\footnotetext{
' Revisão do texto sob a responsabilidade de: Leda Farah
}

(C) ETD - Educação Temática Digital Campinas, SP $\quad$ v.20 $\quad$ n.3 $\quad$ p. 679-698 jul./set.2018

